\title{
Medicinal Plants in the Management of Cancer: A Review
}

\begin{abstract}
Globally cancer is one of the commonly life-threatening diseases which severely affect the human being. It is recognized by the uncontrollable division of cells. There is a demand for new methods to prevent this disease. Conventional therapies have several adverse effects on the on healthy cells, therefore, an alternative and effective medication are required to combat this disease. Benefits of using plant derive product over synthetic medicine have increased the importance of medicinal plants in the field of healthcare. Many plants derive product shows potent in cancer treatment by inhibiting cancer activating enzymes, stimulate DNA repair mechanism, induce antioxidant action, and promote protective enzymes production. In the present review, an effort has been done to provide information about the various compounds present in the medicinal plants that have shown potent activity against various forms of cancer.
\end{abstract}

Keywords: Anticancer activity; Cytotoxic effect; Medicinal plants; Phytocompounds

Review Article
Volume 9 Issue 2 - 2017
Arpita Roy and Navneeta Bharadlvaja*
Plant Biotechnology Laboratory, Department of Biotechnology,
Delhi Technological University, India
*Corresponding author: Navneeta Bharadvaja, Plant
Biotechnology Laboratory, Department of Biotechnology,
Delhi Technological University, New Delhi-110042, India,
Email: navneetab@dce.ac.in
Received: September 04, 2017 | Published: October 24,
2017

\section{Introduction}

Plants have always been a basis for the traditional medicine systems and they have provided continuous remedies to the mankind for thousands of years. Knowledge of the medicinal plants for the preparation of various drugs has been of great significance [1]. Medicinal plants are considered as a rich source of wide variety of ingredients which can be used for the development of drug. Cancer is a one of the deadly diseases which is characterized by irregular cell proliferation. It is the major health issue in developing and developed countries. The most common reason behind the cancer is changing lifestyle and due to this it become a global problem across the world. Thus there is an urgent need to find better treatment possible for this disease. As chemotherapy and radiation therapy causes various side effects, so there is a necessity to discover novel agents for the treatment of this disease; it could be possible with the use of naturally occurring compounds [2].

According to World Health Organization (WHO), more than 14 million people diagnosed with cancer and 8 million dies in 2012 (www.who.int). High mortality and incidence make it an important public health and economic issue which requires an effective prevention. Radiotherapy, immunotherapy and chemotherapy are the most common method used for the cancer treatment, but these techniques adversely affect the healthy cells. Thus, inhibition of damaging behavior to the healthy tissues with the use of commonly used therapies motivates to explore the new safe methods to treat cancer. Interestingly, natural drugs show an alternative to limit the emergence and spread of cancer [3]. The endless diversity of the plant kingdom, presents an extraordinary opportunity to develop novel anticancer drugs. Isolation and identification of compounds that are derived from plant source continues to expand, particularly in the cancer chemotherapy drugs discovery. In this sense, novel anticancer drugs developed from natural resources may increase the efficacy of conventional chemotherapeutic drugs. Numerous phytochemicals derived from plant resources interfere with the specific stage of carcinogenesis [4]. Compounds isolated from plants are natural and have an advantage over synthetic chemical compounds as they are readily available in nature, since they are natural products so the problem of acquiring resistance against these compounds is minimized to a very great extent. Several studies have been done on naturally occurring compounds which are known to possess cytotoxicity effects and have the potential to destroy cancer cells. Therefore in this review an effort has been made to give an insight about some of the medicinal plants that posses anticancer activity.

\section{Anticancer Activity of Medicinal Plants}

Medicinal plants have various advantages over chemical products, because plant derived compounds are more tolerated and non-toxic to the normal human cells. Already available conventional therapies for the treatment of cancer are radiotherapy and chemotherapy and they have possesses various side effects like neurological, cardiac, renal and pulmonary toxicity, which seriously affects the health of the person. Therefore, an alternative method is required to develop that include less toxic and more potent anticancer drug as compare to the drugs available in the market.

\section{Andrographis paniculata}

It is commonly known as kalmegha in Hindi and king of bitters in English and belongs to Acanthaceae family. It is found in the India and Sri Lanka. Generally roots and leaves are used for the medicinal purpose; extract of this plant contains flavonoids, stigmasterols and diterpenes [5]. The main compound of this plant is the andrographolide which is a diterpene, it is colorless crystilline in nature and bitter in taste. Leaves contains highest amount of andrographolide (approxemately 2.25\%) while the seeds contains very low amount of this compound. Studies in mice have shown that Andrographis paniculata stimulates 
immune system and activates both the antigen specific and non specific immune response [6]. Due to this ability, plant is effective against various oncogenic and infectious agents [6]. Andrographolide shows cytotoxic effects against various cancer cells [7]. It shows cytotoxic effect against breast cancer cells (MCF7), P388 lymphocytic cells and colon cancer cells (HCT-116) [8]. Andrographolide shows inhibition of growth in colon cancer cell line HT 29 and enhance growth and division of human peripheral blood lymphocytes on mouse myeloid leukemia M1 cell lines [8].

\section{Azadirachta indica}

It belongs to the Meliacear family and commonly known as neem or the Indian liliac. It is a tree native to the Indian subcontinent and belongs to the family Meliaceae. The lead anticancer component in neem is limonoidsincluding azadirachtin and nimbolide that induce apoptosis of tumor cells by targeting different cell signaling pathways. There are various theories of cell apoptosis by neem such as activation of proapoptotic proteins like Bax and Bak to permeabilize mitochondria and inhibiting the activity of Bcl-2 and mutant p53 in the 7, 12-dimethylbenz (a) anthracene (DMBA)-induced cancer cells. However there is no evidence on the culminating reasons of neem induced apoptosis. A study on limonoids shows that neem exhibits caspase dependent cell apoptosis and release reactive oxygen species to inhibit metastasis [9]. The neem leaf glycoprotein regulates the activity of M2 macrophages, by converting it to M1 phenotypes in tumor core. This restricts the growth of melanoma and prevents the relapse of tumor by disseminating tumor mass. The vital properties of neem components on tumor cells include enhancing immune response, inhibiting cell proliferation, inducing cell apoptosis, suppression of cancer angiogenesis, and restoration of cellular reduction/ oxidation (redox) balance. Neem extracts enhance the efficacy of certain chemotherapeutic drugs and sensitize malignant cells to immunotherapy and radiotherapy.

\section{Boesenbergia pandurata}

It belongs to the Zingiberaceae family and it's a perennial herb. It is native to the South east Asia and commonly called as finger root or Chinese ginger The active compounds in B. pandurata are boesenbergin, cardamonin, pinostrobin, pinocembrin, panduratin $\mathrm{A}$ and 4-hydroxypanduratin A. These compounds act as antioxidant, antibacterial, antifungal, anti-inflammatory, antitumor and anti-tuberculosis agents. A cyclohexenylchalcone derivative, Panduratin A, present in B. pandurate is shown to inhibit the growth and induce apoptosis of HT-29 colon cancer cells. A study reported that Panduratin A arrested the cancer cell lines A549 non-small cell lung cancer; PC3 and DU145 prostate cancer cells and MCF-7 breast cancer cells and illustrated proapoptotic activities. Mohd Isa et al. [10] investigated the anticancer role of Boesenbergin a (BA) isolated from Boesenbergia rotunda in human non-small cell lung cancer (A549) cells. BA arrested the cell cycle by accumulating the cells in sub G1 phase. BA stimulated the expression of pro-apoptotic Bcl-2 family members, caspase $3 / 7$, 9 and 8.The study thus concludes that BA could be a promising agent for the treatment of lung cancer [10].

\section{Boswellia serrata}

It is belongs to Bursersceae family and found in India North Africa, and Middle East. It is commonly known as olibanum or
Indian olibanum. It contains various compounds like terpenoids, oils and sugars. The main constitute of this plant is Boswellic acid [11]. Gummy exudates of this plant are associated with the therapeutic effect which includes anti-arthriticc, astringent, stimulant and anti-septic effects. Acetyl-11-keto- $\beta$-boswellic acid which is an active compound of this plant shows potential activity to inhibit tumor angiogenesis through the vascular endothelial growth factor signaling. Studies showed that treatment with acetyl-11-keto- $\beta$-boswellic acid (dose-10mg/kg) suppress tumor growth in xenograft mice with human prostate [12]. This shows the anti-tumor activity of this plant.

\section{Capparis spinosa}

It belongs to the Capparaceaen family and an important culinary ingredient in Mediterranean and Middle Eastern cuisines. It is known as Himsra, Cabra in Sanskrit. Caper constitutes various volatile and nonvolatile compounds like flavonol glycoside, rutinand 5-caffeoyl-quinic acid those are potent anti-cancer agents. A protein analogus to imidazoleglycerol phosphate synthase was purified from fresh Caper seeds, that inhibited proliferation of hepatoma HepG2 cells, colon cancer HT29 cells and breast cancer MCF-7 cells [13]. Essential oils and aqueous infusions extracted from Caper have shown significant inhibitory effect on HT-29 cell proliferation and on nuclear factor kB (NF$\mathrm{kB}$ ) activity in a dose dependent manner. Caper essential oil and aqueous infusion ceased the cells in G2/ M phase of cell cycle. A study has reported C. spinosa extract mediated apoptosis through permeabliztion of mitochondria and activation of Caspase 9 in SGC-7901 cells [14].

\section{Centella asiatica}

It belongs to the Apiaceae family and commonly known as brahmamanduki in Hindi, mandukaparni in Sanskrit and pennywort in English. It is commonly found in the India, Australia, Pacific Islands, New Guinea, Iran and Malaysia. It contains numerous compounds such as asiaticoside, pectic acid, hydrocotyline, sterol, flavonoid, vallerine, ascorbic acid and thankunosides [15]. Partially purified fraction of Centella asiatica suppressed mouse lung fibroblast cell proliferation and oral administration slowed the solid development and ascites tumours [16]. Pre-treatment with this plant increase the survival time of irradiated animals and show protection against radiation induces damage in liver [17]. This plant shows inhibition in lipid peroxidation in various organs like lungs, liver, heart, brain, spleen and kidney and shows potential towards the cancer inhibition [18].

\section{Curcuma longa}

It is belongs to the Zingiberaceae family and commonly known as haldi in Hindi, harida in Sanskrit and turmeric in English. Curcumin is the active ingredient of this plant, which is a polyphenol derived from plant rhizome and this plant is used for both cancer prevention and treatment. Numerous studies showed that curcumin induces apoptosis, interfere with progression of cell cycle and inhibits proliferation [19]. Curcumin also showed colon and gastric cancer prevention in rodents [20]. Curcumin shows protective effect by inhibiting the growth of several angiogenesis associates and tumor associated genes [21]. Curcumin shows anticancer activity by inhibiting the proliferation of tumor cells 
[22]. Curcumin possess anti-proliferative property by down regulating the numerous gene expressions which includes activator protein 1, NF- kappa B, cycloxygenase 2, epidermal growth receptor 1 , nitric oxidase synthase and tumor necrosis factor [22].

\section{Panax ginseng}

It belongs to the Araliaceae family and ound in the Korea, China, Japan, United States and Russia. It active compound is ginsesosides which is a steroidal saponin [23]. It posses antiinflammatory and immune-modulatory activity and also helps in the appetite stimulation, physical stamina improvement, memory enhancement and behavior [24]. Anticancer activity of ginsenosides is due to the induction of cell death and its other properties as an anti-invasion, anti-angiogenesis and antiproliferation activity [25].

\section{Psidium cattleianum}

It is commonly known as the strawberry guava or cattley guava is a native to temperate zones of Brazil. More than 200 volatile compounds have been identified in the fruit oil of P. cattleianum. In a study conducted by Moon et al. 2011, the anticancer properties of chloroform extract of $P$. cattleianum leaves were reported. The effect of chloroform fraction of guava leaf extract was evaluated against various cancer cell lines. Significant cytotoxicity was observed against SNU-16, a gastric cancer cell line. Strawberry guava acts as an inducer of apoptosis and inhibits the proliferation of cancer cells. It induces apoptosis by stimulating the activities of proapoptotic factors like caspase-8, caspase-3 Bcl-2, Bax and poly (ADP-ribose) polymerase (PARP). The chloroform extract of guava leaves ceases the SNU-16 cancer cell lines in G1 phase of the cell cycle thus acting as an anti-proliferative agent.

\section{Phyllanthus Amarus}

It belongs to the Euphorbiaceae Family and known as jaramla in Hindi, bhumyamalaki in Sanskrit and stone breaker in English. It is found in the Asia (warmer parts of India). Whole plant, shoots, roots and leaves are utilized for the medicinal purpose. $P$. amarus contains flavanoids, tannins and lignans and used in the liver, stomach, kidney, spleen and genitourinary system problems. Oral administration of $P$. amarus extract reduce tumor size and increase life span in mice bearing Erlich ascites carcinoma and Dalton's lymphoma ascites [26]. Anticancer activities of this plant are due to the ability to induce cell cycle arrest, interfere with DNA repair and inhibition of metabolic activation of carcinogenic compounds [26]. Extract of P. amarus also showed anti-angiogenic effects in mice (bearing Lewis lung carcinoma) by interfering with the vascular endothelial cells migration [27].

\section{Plumbago zeylanica}

It belongs to the Plumbaginaceae family and commonly known as white leadwort, chitrak and Ceylon leadwort. It is found in the warmer part of India and Sri Lanka. Several studies reveal the presence of various phytocompounds in this plant which includes plumbagin, plumbagin acid, coumarins, saponaretin, isoaffinetin, isoorientin, steroids, glucosides and psoralen [15]. This plant shows therapeutic activity against skin diseases, rheumatic pain, wounds and scabies [28]. Plumbagin is a napthoquinone which is isolated from the roots of this plant and it possess anti-tumor activity by controlling the hormone refractory invasive prostate cancer. Inhibitory effect of plumbagin against various molecular targets (STAT-3, AKT and PI-3K) results in the growth inhibition and invasion of prostate cancer. Plumbagin shows apoptosis induction in cancer cells and also inhibits growth of these cells.

\section{Rhinacanthus nasutus}

It is belongs to the Acanthaceae family and found in the sub-contenental parts of India, China and Southeast Asia. It is commonly known as 'snake jasmine'. It contains rhinacathins (A-D,G-Q), naphthoquinone, lignin groups and rhinacanthone [29]. This plant shows potential in the treatment of pulmonary tuberculosis, eczema, diabetes and herpes. Studies showed that rhinacanthins $\mathrm{M}, \mathrm{N}$ and $\mathrm{Q}$ inhibits human cancer cell (HeLa, HepG2 and KB) growth and normal Vero cells. Rhinacanthins N partially arrest the $\mathrm{M}$ phase cells and prevents from further damage and repair cell defects [30].

\section{Scutellaria baicalensis}

It belongs to the Lamiaceae family and found in eastern Asia. It is commonly known as Baikal, scute and scutellaria. It contains chalcones, anthocyanidins, flavanones, flavonols, flavanonols and flavones. Its anti-tumor property is due to the presence of wogonosid, wogonin, baicalein and skullcapflavone II. All these compounds (at micro molar concentration) show inhibitory effects against human tumor cell line 529L and LXFL proliferation. Baicalein inhibits the activity of 12-lipoxygenase and contributes to the anti-cancer activity against various other cancers [31]. It also possesses ant-inflammatory, anti-diabetic, anti-tumor, hepatopretective, anti-anxiety and anti-hypertensive effects [32].

\section{Tinospora cordifolia}

It belongs to Menispermaceae family and commonly found in Sri Lanka, India, Myanmar and China. Stem and roots contain important alkaloids. It is known as 'giloya' in Hindi, 'guduchi' in Sanskrit and heartleaf moonseed plant in English. Root of this plant contains various alkaloids which includes tinosporin, choline, isocolumbin, columbin, tetrahydroplamatine, magnoflorimne and palmatin [33]. Tinospora cordifolia stem is generally used for the treatment of fever, dyspepsia, jaundice, skin and urinary disease [34]. In-vitro study shows Tinospora cordifolia able to kill HeLa cells this shows the potential of this plant as an anticancer agent. Tinospora cordifolia extract shows dose dependent cell death as compared to the controls [35]. Dichloromethane extract of $T$. cordifolia showed anticancer activity in mice transplanted with Ehrlich ascites carcinoma [36].

\section{Vitis vinifera}

It belongs to the Vitaceae family and commonly known as grape vine. Grape extracts exhibit cytotoxic effect against PC-3, A-549 and MCF-7 cancer cells. Extracts isolated from the grape seeds andstems demonstrated antitumor activity in human breast cancer cell lines MCF-7 and MDA-MB-23), colon (HT29), renal (786-0 and Caki-1), thyroid (K1), hepatocellular carcinoma cell lines, oral squamous cell carcinoma and normal human 
fibroblasts [37]. Grape skin possesses a chemopreventive agent, Resveratrol that induces autophagy and acts as an anticancer agent. In a clinical trial methanolic extracts from Greek raisins have been reported to demonstrate a decrease in gastric cancer cell proliferation and mRNA levels of ICAM-1 in TNF-alpha stimulated cells with an induction in cell apoptosis and inhibition of inflammation [38].

\section{Withania somnifera}

It is commonly known as ashwagandha in Hindi and Sanskrit, winter cherry in English. It belongs to the Solanaceae family and a subtropical shrub found in Mediterranean, Africa and India. It contains withanolides, withaferins, anferine, isopellertierine and sitoindosise. Due to its medicinal properties, leaves and roots have been used in the Indian traditional system of medicine and marketed globally. Extract of Withania somnifera modulates various biological responses [39]. It has been used in various preparations for its anti-stress, anti-ageing, anti-peroxidative, anti-inflammatory, anti-oxidant, anti-tumor, cardiotonic, and immunomodulatory properties [40]. Withanolide A and withaferin A is the main constitute of this plant. Withaferin A which is mostly present in the leaves produces rapid apoptosis in the cancer cells [40]. Cell signaling pathways by this plant formulation largely depends up on the high content of withferin A present in it [40]. Formulation of Withania somnifera showed induction in cell cytotoxicity in various human cancer cell lines [18]. Withania somnifera formulation also up regulates population of $\mathrm{T}$ cell population in mice (bearing tumor) with increased expression of IL-2 and IFN-gamma levels [41].

\section{Xanthium strumarium}

It is belongs to the Asteraceae family and commonly known as burweed or cocklebur. It is found in the North America and possesses anti-bacterial, anti-fungal, anti-tumor, anti-tussive, antiinflammatory, anti-mitotic, anti-malarial, anti-oxidant, analgesic and insecticidal activities. It contains xanthinin, xanthumin, xanthostrumarin, xanthatin, phytosterols, xanthanolides, isoxanthonol, xanthanol and xanthinosin. 8-epi-xanthatin and its epoxide shows anti-tumor activity by inhibiting the tumor cell lines proliferation. 8-epi-xanthatin acts as a farnesyl transferse inhibitor and also inhibits microtubules interfering agents, this shows the potential of 8-epi-xanthatin in the anti-cancer activity [42].

\section{Ziziphus nummularia}

It belongs to the Rhamnaceae family and found in Iran, India, Iraq, Israel, Pakistan and Afghanistan. Stem, bark, roots seeds and flowers of this plant used for the medicinal purpose. It is known as harbor in Hindi, bhukamtaka sukhsharanphala in Sanskrit and wild jujube in English. Betulinic acid and betulin (present in stem and bark) is the active constitute of this plant which shows anti-tumor activity [43]. Betulinic acid shows cytotoxicity against various tumor cell lines and induces apoptosis by topoisomerase I inhibition, reactive oxygen species generation, angiogenesis inhibition and pro-growth transcriptional activator modulation [44] Betulinic acid also induces apoptosis by CD 95 and p53 independent mechanism, these mechanisms shows the potential of this compound against the cancer cells [43-54].

\section{Conclusion}

Cancer is one of big problems in both developing and developed countries. Various synthetic drugs have been used to treat cancer but they have limitations due to their toxic effects on the normal health cells. Therefore, there is demand for an alternative medicine for the treatment of cancer. Medicinal plant largely contributed to human being health and it contains various secondary metabolites which show their potential towards numerous disease treatments. Anti-cancer agents derived from the plant source have largely contributed to the development of new drugs. Extracts of various medicinal plants and their secondary metabolites are responsible for the anti-cancer activity. Discovery and development of plant derive drugs shows a great promise for future. This review contains medicinal plants with their secondary metabolites that show anti-cancer activity. Invitro studies have showed the potential of secondary metabolites in the anti-cancer activity and plant metabolites mentioned in this review possesses variety of mechanisms that contributes to their anti-cancer nature. Therefore in this review effort has been made to summarized the various medicinal plants and their important phytocompounds used for the treatment of cancer.

\section{Acknowledgement}

I would like to acknowledge Delhi Technological University for providing the facilities to carry out this review successfully.

\section{Conflict of Interest}

All the authors have no conflict of interest.

\section{References}

1. Atanasov AG, Waltenberger B, Pferschy-Wenzig EM, Linder T, Wawrosch C,etal.(2015) Discovery and resupply of pharmacologically active plant-derived natural products: A review. Biotechnology Adv 33(8): 1582-1614.

2. Dias DA, Urban S, Roessner U (2012) A Historical Overview of Natural Products in Drug Discovery. Metabolites 2(2): 303-336.

3. Saini RK, Chouhan R, Bagri PL, Bajpai AK (2012) Strategies of Targeting Tumors and Cancers. Journal of Cancer Research Updates 1: $129-152$.

4. Wang H, Khor TO, Shu L, Su ZY, Fuentes F, et al. (2012) Plants Against Cancer: A Review on Natural Phytochemicals in Preventing and Treating Cancers and Their Druggability. Anticancer Agents Med Chem 12(10): 1281-1305.

5. Siripong P, Kongkathip B, Preechanukool K, Picha P, Tunsuwan K, Taylor WC (1992) Cytotoxic diterpenoid constituents from Andrographis paniculatanees leaves. Science Asia 18: 187-194.

6. Puri A, Saxena R, Saxena RP, Saxena KC, Srivastava V, et al. (1993) Immunostimulant agents from Andrographis paniculata. J Nat Prod 56(7): 995-999.

7. Kumar RA, Sridevi K, Kumar NV, Nanduri S, Rajagopal S (2004) Anticancer and immunostimulatory compounds from Andrographis paniculata. J Ethnopharmacol 92(2-3): 291-295.

8. Jada SR, Subur GS, Matthews C, Hamzah AS, Lajis NH, et al. (2007) Semisynthesis and in vitro anticancer activities of andrographolide analogues. Phytochemistry 68(6): 904-912. 
9. Yadav N, Kumar S, Kumar R, Srivastava P, Sun L, et al. (2015) Mechanism of neem limonoids-induced cell death in cancer: Role of oxidative phosphorylation. Free Radic Biol Med 90: 261-271.

10. Mohd Isaa N, Abdula AB, Abdelwahabb SI, Abdullahc R, Sukarid MA, et al. (2012) Boesenbergin A, a chalcone from Boesenbergia rotunda induces apoptosis via mitochondrial dysregulation and cytochrome c release in A549 cells in vitro: Involvement of HSP70 and $\mathrm{Bcl} 2 / \mathrm{Bax}$ signalling pathways. J Funct Foods 5(1): 87-97.

11. Krieglstein CF, Anthoni C, Rijcken EJ, Laukotter M, Spiegel HU, et al (2001) Acetyl-11-keto-beta-boswellic acid, a constituent of a herbal medicine from Boswellia serrata resin, attenuates experimental ileitis. Int J Colorectal Dis 16(2): 88-95.

12. Pang X, Yi Z, Zhang X, Sung B, Qu W, et al. (2009) Acetyl-11-ketob-boswellic acid inhibits prostate tumor growth by suppressing vascular endothelial growth factor receptor 2-mediated angiogenesis. Cancer Res 69(14): 5893-5900.

13. Lam SK, Ng TB (2009) A protein with antiproliferative, antifungal and HIV-1 reverse transcriptase inhibitory activities from caper (Capparis spinosa) seeds. Phytomedicine 16(5): 444-450.

14. Kulisic-Bilusic T, Schmöller I, Schnäbele K, Siracusa L, Ruberto G (2012) The anticarcinogenic potential of essential oil and aqueous infusion from caper (Capparis spinosa L.). Food Chem 132(1): 261267.

15. Roy A, Bharadvaja N (2017) Silver Nanoparticles Synthesis from a Pharmaceutically Important Medicinal Plant Plumbago Zeylanica. MOJ Bioequiv Availab 3(5): 00046.

16. Babu TD, Kuttan G, Padikkala J (1995) Cytotoxic and anti-tumour properties of certain taxa of Umbelliferae with special reference to Centella asiatica (L.) Urban. J Ethnopharmacol 48(1): 53-57.

17. Verma S, Sharma D, Bansal K (2011) Podophyllotoxin and their glycosidic derivatives. Pharmacophore 2(2): 124-134.

18. Desai AG, Qazi GN, Ganju RK, El-Tamer M, Singh J, et al. (2008) Medicinal Plants and Cancer Chemoprevention. Curr Drug Metab 9(7): 581-591.

19. Chen HW, Huang HC (1998) Effect of curcumin on cell cycle progression and apoptosis in vascular smooth muscle cells. $\mathrm{Br}$ J Pharmacol 124(6): 1029-1040.

20. Ikezaki S, Nishikawa A, Furukawa F, Kudo K, Nakamura H, et al. (2001) Chemopreventive effects of curcumin on glandular stomach carcinogenesis induced by N-methyl-N'-nitro-N nitrosoguanidine and sodium chloride in rats. Anticancer Res 21(5): 3407-3411.

21. Kerbel R, Folkman J (2002) Clinical translation of angiogenesis inhibitors. Nat Rev Cancer 2(10): 727-739.

22. Aggarwal BB, Kumar A, Bharti AC (2003) Anticancer potential of curcumin: preclinical and clinical studies. Anticancer Res 23(1A): 363-398.

23. Attele AS, Wu JA, Yuan CS (1999) Ginseng pharmacology: multiple constituents and multiple actions. Biochem Pharmacol 58(11): 1685-1693.

24. Sun LQ (2004) Information on research and application of Ginseng, the king of traditional and herbal medicines. Asian Journal of Drug Metabolism and Pharmacokinetics 4: 264-282.

25. Yue PY, Mak NK, Cheng YK, Leung KW, Ng TB, et al. (2007) Pharmacogenomics and the Yin/Yang actions of ginseng: antitumor, angiomodulating and steroidlike activities of ginsenosides. Chinese Med 2: 6 .
26. Rajeshkumar NV, Joy KL, Kuttan G, Ramsewak RS, Nair MG, et al. (2002) Antitumour and anticarcinogenic activity of Phyllanthus amarus extract. J Ethnopharmacol 81(1): 17-22.

27. Huang ST, Yang RC, Lee PN, Yang SH, Liao SK, et al. (2006) Anti-tumor and anti-angiogenic effects of Phyllanthus urinaria in mice bearing Lewis lung carcinoma. Int Immunopharmacol 6(6): 870-879.

28. Gupta MM, Verma RK, Uniyal GC, Jain SP (1993) Determination of plumbagin by normal-phase high-performance liquid chromatography. J Chromatogr A 637(2): 209-212.

29. Thirumurugan RS, Kavimani S, Srivastava RS (2000) Anti-tumour activity of rhinacanthone against Dalton's ascitic lymphoma. Biol Pharma Bull 23(12): 1438-1440.

30. Siripong P, Yahuafai J, Shimizu K, Ichikawa K, Yonezawa S, et al (2006) Antitumor activity of liposomal naphthoquinone esters isolated from Thai medicinal plant: Rhinacanthus nasutus Kurz. Biol Pharma Bull 29(11): 2279-2283.

31. Zhou Y, Gao W, Li K. Chinese herbal medicine in the treatment of lung cancer. Asian J Tradit Med 3(1): 1-11.

32. Bhandari M, Bhandari A, Prakash R, Bhandari A (2010) Scutellaria baicalensis Georgi: a rising paradigm of herbal remedies. Pharmaceutical Sci 1: WMC001105.

33. Sultana N, Lee NH (2007) Antielastase and free radical scavenging activities of compounds from the stems of Cornus kousa. Phytother Res 21(12): 1171-1176.

34. Singh SS, Srivastava S, Gupta VS, Patro B, Ghosh AC (2003) Chemistry and medicinal properties of Tinospora cordifolia (guduchi). Ind J Pharmacol 35: 83-91.

35. Jagetia GC, Nayak V, Vidyasagar MS (1998) Evaluation of the antineoplastic activity of guduchi (Tinospora cordifolia) in cultured HeLa cells. Cancer Lett 127(1-2): 71-82.

36. Jagetia GC, Rao SK (2006) Evaluation of the antineoplastic activity of guduchi (Tinospora cordifolia) in Ehrlich ascites carcinoma bearing mice. Biol Pharm Bull 29(3): 460-466.

37. Kaur M, Agarwal C, Agarwal R (2009) Anticancer and Cancer Chemopreventive Potential of Grape Seed Extract and Other GrapeBased Products. J Nutr 139(9): 1806S-1812S.

38. Kaliora AC, Kountouri AM, Karathanos VT, Koumbi L, Papadopoulos NG, et al. (2008) Effect of Greek raisins (Vitis vinifera L.) from different origins on gastric cancer cell growth. Nutr Cancer 60(6): 792-799.

39. Winters M (2006) Ancient medicine, modern use: Withania somnifera and its potential role in integrative oncology. Altern Med Rev 11(4): 269-277.

40. Malik F, Kumar A, Bhushan S, Khan S, Bhatia A, et al. (2007) Reactive oxygen species generation and mitochondrial dysfunction in the apoptotic cell death of human myeloid leukemia HL-60 cells by a dietary compound withaferin A with concomitant protection by $\mathrm{N}$-acetyl cysteine. Apoptosis 12(11): 2115-2133.

41. Malik F, Singh J, Khajuria A, Suri KA, Satti NK, et al. (2007) A standardized root extract of Withania somnifera and its major constituent withanolide-A elicit humoral and cell-mediated immune responses by up regulation of Th1-dominant polarization in BALB/c mice. Life Sci 80(16): 1525-1538.

42. Kim YS, Kim JS, Park SH, Choi SU, Lee CO, et al. (2003) Two cytotoxic sesquiterpene lactones from the leaves of Xanthium strumarium and their in vitro inhibitory activity on farnesyltransferase. Planta Med 69(4): 375-377. 
43. Sarek J, Kvasnica M, Urban M Klinot J, Hajduch M (2005) Correlation of cytotoxic activity of betulinines and their hydroxy analogues. Bioorg Med Chem Lett 15(19): 4196-200.

44. Eiznhamer DA, Xu ZQ (2004) Betulinic acid: a promising anticancer candidate. IDrugs 7(4): 359-373.

45. Lee EH, Park HR, Shin MS, Cho SY, Choi HJ, Shin KS (2014) Antitumor metastasis activity of pectic polysaccharide purified from the peels of Korean Citrus Hallabong. Carbohydr Polym 111: 72-79.

46. Pahadiya S, Sharma J (2003) Alteration of lethal effects of gamma rays in Swiss albino mice by Tinospora cordifolia. Phytother Res 17(5): 552-554.

47. Sharma J, Sharma R (2002) Radioprotection of Swiss albino mouse by Centella asiatica extract. Phytother Res 16(8): 785-786.

48. Serasanambati M, Chilakapati SR (2015) Anticancer Activitsy of Methanolic Extract of Berberis aristata in MCF-7 Human Breast Cancer Cell Lines. Int Journal of Life science biotechnology and pharma research 4(1): 31-35.
49. Sumner J (2000) The Natural History of Medicinal Plants. Timber Press, USA, p. 17.

50. Roy A, Kundu K, Saxena G, Kumar L, Bharadvaja N (2016) Effect of different media and growth hormones on shoot multiplication of in vitro grown Centella asiatica accessions. Advanced Techniques in Biology \& Medicine 4: 172.

51. Zu Y, Yu H, Liang L, Fu Y, Efferth T, et al. (2010) Activities of Ten Essential Oils towards Propionibacterium acnes and PC-3, A-549 and MCF-7 Cancer Cells. Molecules 15(5): 3200-3210.

52. Kanti GK, Sarkar M, Ghosh S, Saha A, Ghosh T, et al. (2016) Neem leaf glycoprotein regulates function of tumor associated M2 macrophages in hypoxic tumor core: Critical role of IL-10/STAT3 signaling. Mol Immunol 80: 1-10.

53. Chattergy A, Prakash S (1999) The Treatise on Indian Medicinal Plants. India, pp. 240-242.

54. Campbell CT, Prince M, Landry GM, Kha V, Kleiner HE (2007) Proapoptotic effects of 1 '-acetoxychavicol acetate in human breast carcinoma cells. Toxicol Lett 173(3): 151-160. 